2011-11

\title{
Automatic and ironic behavior are both mediated by changes in the self-concept
}

Wyer, Natalie

http://hdl.handle.net/10026.1/2936

10.1016/j.jesp.2011.05.008

Journal of Experimental Social Psychology

Elsevier BV

All content in PEARL is protected by copyright law. Author manuscripts are made available in accordance with publisher policies. Please cite only the published version using the details provided on the item record or document. In the absence of an open licence (e.g. Creative Commons), permissions for further reuse of content should be sought from the publisher or author. 
Provided for non-commercial research and education use. Not for reproduction, distribution or commercial use.

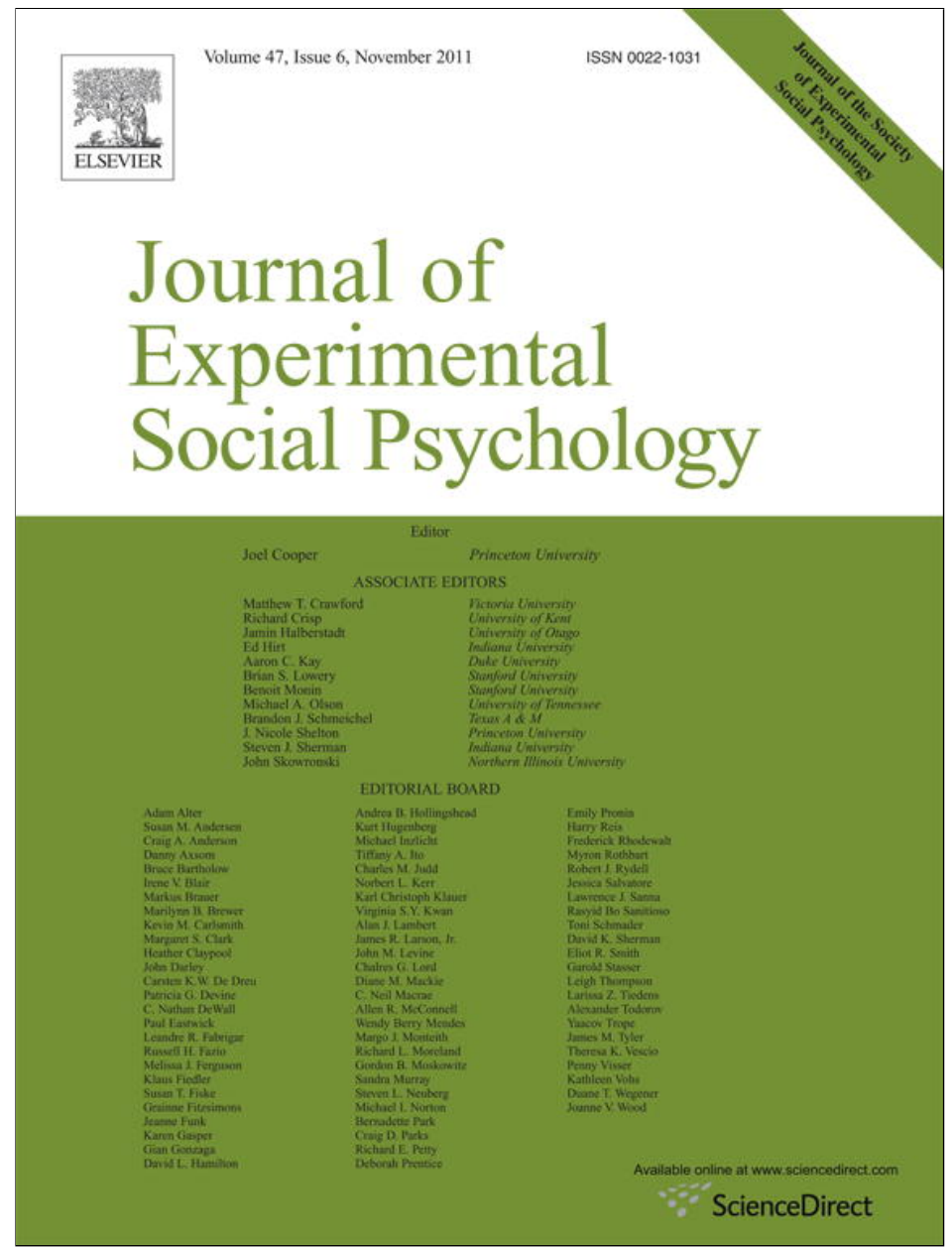

This article appeared in a journal published by Elsevier. The attached copy is furnished to the author for internal non-commercial research and education use, including for instruction at the authors institution and sharing with colleagues.

Other uses, including reproduction and distribution, or selling or licensing copies, or posting to personal, institutional or third party websites are prohibited.

In most cases authors are permitted to post their version of the article (e.g. in Word or Tex form) to their personal website or institutional repository. Authors requiring further information regarding Elsevier's archiving and manuscript policies are encouraged to visit:

http://www.elsevier.com/copyright 
FlashReport

\title{
Automatic and ironic behavior are both mediated by changes in the self-concept
}

\author{
Natalie A. Wyer ${ }^{\mathrm{a}, *}$, Helen Neilens ${ }^{\mathrm{a}}$, Timothy J. Perfect ${ }^{\mathrm{a}}$, Giuliana Mazzoni ${ }^{\mathrm{b}}$ \\ a University of Plymouth, UK \\ ${ }^{\mathrm{b}}$ University of Hull, UK
}

\section{A R T I C L E I N F O}

\section{Article history:}

Received 3 March 2011

Revised 2 May 2011

Available online 14 May 2011

\section{Keywords:}

Stereotype suppression

Priming

Behaviour

Active self

\begin{abstract}
A B S T R A C T
Recent accounts suggest that prime-to-behavior effects are mediated by changes to the active self-concept. Likewise, recent reports of post-suppression behavioral rebound have attributed changes to behavior to changes in the self-concept. According to such accounts, whenever an activated trait or stereotype can be easily incorporated into the active self, behavioral assimilation (i.e., behavior consistent with the activated concept) is likely to ensue. Yet, little evidence has emerged to directly support the mediating role of changes to the self-concept. The present research was designed to examine whether changes to the active self-concept are responsible for changes in behavior following stereotype suppression and priming. Participants who suppressed or were primed with stereotypes of the elderly were more likely to endorse stereotypic traits as self-descriptive and to behave in stereotypic ways. Critically, the former effect significantly mediated the latter. Implications for theories of concept activation and behavior are discussed.
\end{abstract}

(C) 2011 Elsevier Inc. All rights reserved.
Activating social concepts, through either direct or indirect means, has important consequences for how both the self and others are construed. Over thirty years' worth of research has demonstrated that when traits or stereotypes are accessible in memory, perceivers become more likely to use them to interpret others' behavior (e.g., Devine, 1989; Higgins, Rholes, \& Jones, 1977), to guide their own behavior (e.g., Bargh, Chen, \& Burrows, 1996; Wyer, Mazzoni, Perfect, Calvini, \& Neilens, 2010), and to shape the self-concept (e.g., DeMarree, Wheeler, \& Petty, 2005; Skowronski, Sedikides, Heider, Wood, \& Scherer, 2010; Wyer, Mazzoni, et al., 2010). Indeed, the link between concept activation and behavior ranks among the moststudied phenomena in the past 15 years (see Dijksterhuis \& Bargh, 2001; Smeesters, Wheeler, \& Kay, 2010). The results of dozens of studies suggest that individuals who are primed with a stereotype are subsequently more likely to behave as if that stereotype applied to them personally.

Despite numerous demonstrations that even subtle exposure to stereotype-related cues is sufficient to elicit observable changes in behavior, there have been relatively few direct investigations into the cognitive mechanisms that are responsible for such effects. Two principal theories have been advanced. The ideomotor model, advocated by Dijksterhuis and Bargh (2001), argues that mere exposure to a social concept activates (among other things) behavioral representations associated with that concept. These

\footnotetext{
* Corresponding author at: School of Psychology, University of Plymouth, Drake Circus, Plymouth PL4 8AA, UK.

E-mail address: natalie.wyer@plymouth.ac.uk (N.A. Wyer).
}

representations, in turn, directly produce behavior. For example, when exposed to the concept 'elderly,' behavioral representations like 'moving slowly' or 'being forgetful' are activated and subsequently produce slower movements and more forgetfulness. According to this view, the perception-behavior link is direct and unmediated by other cognitive processes. In other words, more complex cognitive operations on primed stereotypes are not necessary to produce stereotypic behavior.

An alternative account has been proposed by Smeesters et al. (2010) (see also Wheeler, DeMarree, \& Petty, 2007). According to their indirect prime-to-behavior model, activating social concepts can bias perceivers' construal of various targets, including the self, others, and the situation. Under many conditions - including those often present in studies of prime-to-behavior effects - an activated concept is most likely to bias self-construal, because the self is the primary focus of attention (see DeMarree \& Loersch, 2009; Wyer, Calvini, Nash, \& Miles, 2010). Changes to self-construal (and behavior) occur when activated stereotypes are incorporated into the 'active' self-concept (e.g., by making congruent self-knowledge selectively accessible; see Mussweiler, 2007 for an alternative view). Returning to the example of activating elderly stereotypes, the indirect model suggests that the subset of self-knowledge that is compatible with those stereotypes (e.g., times when one has been slow or forgetful) becomes more accessible and, consequently, produce stereotype-consistent behavior.

Both models have received extensive empirical support. Yet, there have been comparatively few attempts to determine whether primeto-behavior effects are attributable to either activated behavioral representations alone (as proposed by the ideomotor model) or to changes to the active self-concept (as proposed by the indirect model). 
Indeed, the nature of the ideomotor model makes definitive tests difficult, as the distinguishing feature of the model is that prime-tobehavior effects are unmediated. Thus, support can only be derived by demonstrating that plausible mediating mechanisms fail to account for such effects. In contrast, while there is little direct evidence that changes to the self-concept mediate behavior, other postulates stemming from the indirect model have received empirical support. For example, Smeesters, Wheeler, and Kay (2009) demonstrated that priming influenced behavior by biasing perceptions of one's interaction partner (see also Wyer, Calvini, et al., 2010). Furthermore, Kay and Ross (2003) reported that activating 'competitiveness' led participants to behave more competitively in a prisoner's dilemma game, and this was mediated by perceptions that the game-playing situation was competitive. Such studies provide compelling evidence that not all prime-to-behavior effects are direct and unmediated by higherlevel cognitive processes. Yet, the extent to which the self-concept is directly implicated in such effects has yet to be established.

Notably, Hansen and Wänke (2009) reported initial evidence in support of the indirect model. Participants primed with high-achieving roles (e.g., professors) reported increased self-efficacy, which accounted for superior performance on role-related tasks. While these results are consistent with the view that the self-concept contributes to prime-to-behavior effects, they do not directly address the hypotheses derived from the indirect model - that is, while participants in these studies reported feeling more confident in stereotype-relevant domains, they did not necessarily change their self-concept. Indeed, self-efficacy relates more closely to self-esteem (i.e., one's evaluation of the self) than to self-concept (i.e., the trait attributes one ascribes to the self; see Bong \& Skaalvik, 2003).

The aim of the current work is to clarify whether the self-concept contributes to (i.e., mediates) the effects of concept activation on behavior. In doing so, we also draw on recent work demonstrating that not only priming but also suppressing stereotypes - a process that has been shown to result in stereotype activation (Macrae, Bodenhausen, Milne, \& Jetten, 1994; Wegner, 1994) - produces changes both to the active self-concept and to behavior (Wyer, Mazzoni, et al., 2010). In separate experiments, Wyer, Mazzoni, et al. (2010) demonstrated that participants who suppressed stereotypes of inventors or mathematicians later associated themselves with stereotypic traits (creativity or logic, respectively), and also performed better on tasks requiring stereotype-related skills. Consistent with the active-self account (Wheeler et al., 2007), Wyer, Mazzoni, et al. (2010) attributed these stereotype-consistent performance gains to changes in participants' active self-concepts. Critically however, demonstrating that stereotype suppression independently affects both self-concept and behavior does not establish that the first mediates the second. Thus, this paper aims to provide a direct test of this interpretation and, in doing so, add to the evidence base relating to how prime-to-behavior effects come about.

\section{The present study}

The aim of this study was to establish whether changes in stereotype-relevant behavior following stereotype priming or suppression are mediated by changes in the self-concept. We examined two behavioral measures that have previously been affected by activating elderly stereotypes: walking speed and memory. After suppressing or priming with stereotypes of the elderly, participants walked down a corridor and completed a recall memory task. To the extent that they assimilated to the elderly stereotype, they should walk more slowly and exhibit worse recall. Participants also indicated the extent to which stereotype-related personality traits were selfdescriptive, providing a measure of the active self and a means of testing for mediation of behavior.
Table 1

Trait stimuli used in the self-characterization task.

\begin{tabular}{llll}
\hline & Stereotypic & Counter-stereotypic & Non-stereotypic \\
\hline Positive & Wise & Radiant & Fit \\
& Gentle & Youthful & Intuitive \\
& Kind & Trendy & Confident \\
& Caring & Passionate & Optimistic \\
& Courteous & High-spirited & Brave \\
Negative & Forgetful & Loud & Vain \\
& Grumpy & Violent & Sexist \\
& Stubborn & Abusive & Moody \\
& Narrow-minded & Cruel & Anti-social \\
& Complainer & Intimidating & Jealous \\
\hline
\end{tabular}

\section{Method}

\section{Participants and design}

Seventy-two participants ${ }^{1}$ were tested individually and were randomly assigned to one of three instruction conditions.

\section{Procedure}

The experiment took place in three stages, introduced as unrelated studies. ${ }^{2}$ Instructions for each stage were presented via computer using E Prime software, which allocated participants to condition (rendering the experimenter blind to experimental condition). First, participants were asked to form an impression of five individuals. Participants in the elderly suppression and elderly prime conditions saw photographs of five elderly women, each accompanied by four mundane statements (see Dijksterhuis, Aarts, Bargh, \& van Knippenberg, 2000). Those in the suppression condition were instructed to avoid thinking stereotypically while forming an impression of them. Participants in the control condition saw the statements only. Statements were presented (with or without photographs) on the computer screen in a random order for five seconds each.

Participants were then introduced to the next 'study,' described as investigating the effects of context on memory. They read a list of 30 concrete nouns (e.g., forest, instrument) for an upcoming memory test. They were then instructed via a message on the computer screen to go to another room at the end of the corridor. From a covert location, the experimenter observed participants' movements and recorded the time taken to walk a pre-determined section of the corridor (approximately $10 \mathrm{~m}$ in length). After arriving at the second room, participants were instructed to write down as many words as they recalled from the list presented earlier.

Finally, participants completed a self-characterization task in which they indicated whether each of 30 personality trait words, presented individually on a computer screen, described them by pressing one of two response keys. Stimuli included 10 traits stereotypic of elderly people, 10 counter-stereotypic traits, and 10 stereotype-irrelevant traits (see Table 1). Five positive and five negative traits of each type were included.

\section{Results}

\section{Behavior}

We first standardized both walking time and memory performance, reflecting the latter such that higher scores indicated more

\footnotetext{
${ }^{1}$ Participants' age and gender were not recorded; the sample was drawn from a population characterized by roughly equal numbers of males and females, most in their early-to-mid $20 \mathrm{~s}$

${ }^{2}$ Careful probing during debriefing confirmed that participants were unaware of any connection among the three stages.
} 
a Control $\quad$ Suppression $\quad$ Prime

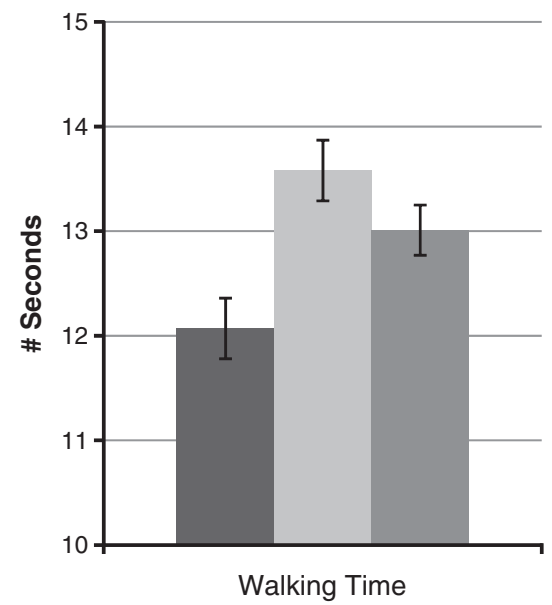

Control Suppression Prime

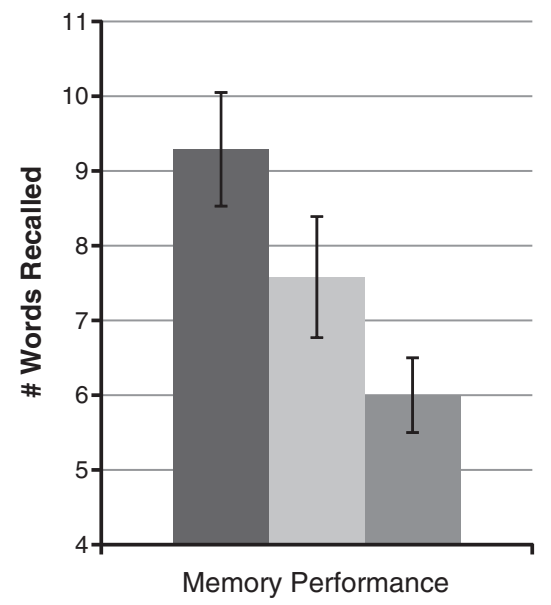

Fig. 1. Mean walking time (left panel) and recall performance (right panel) as a function of instruction condition (with standard errors).

stereotypic behavior (i.e., slower walking, fewer words recalled). For ease of interpretation, raw scores are presented in Fig. 1. We entered both scores as repeated measures in an analysis of variance (ANOVA) with instruction condition as a between-participants factor. The results yielded only the predicted main effect of instruction condition, $F(2,69)=13.91, p<.001, \eta_{p}^{2}=.29$. Bonferroni post hoc tests indicated that both elderly suppression and elderly prime conditions produced more stereotypic behavior than did the control condition (both $p$ 's $<.001)$ but did not differ from each other $(p=.90)$. More detailed analyses confirmed that this was true individually for both measures of stereotypic behavior.

\section{Self-perception}

Participants' responses to the self-characterization task were analyzed for evidence that activating elderly stereotypes led to changes in self-perception. The proportions of 'yes' responses produced for stereotypic, neutral, and counter-stereotypic traits were computed and entered as repeated measures in an ANOVA where instruction condition was a between-participants factor. The analysis yielded a significant main effect of trait type $\left(F(2,138)=48.40, p<.001, \eta_{p}^{2}=.41\right)$. Participants endorsed more stereotypic than neutral or counterstereotypic traits as self-descriptive. However, this effect was qualified by a significant interaction with instruction condition, $F(4,138)=3.03$, $p=.02, \eta_{p}^{2}=.08$. Simple main effects confirmed a marginal effect of trait type among participants in the control condition, $F(2,68)=2.75, p<.08$,

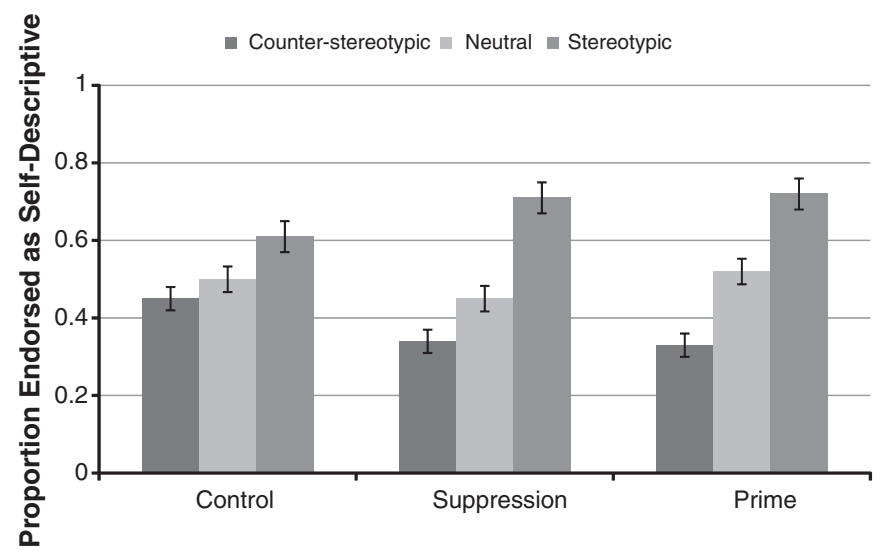

Fig. 2. Endorsement of stereotypic, neutral, and counter-stereotypic traits as selfdescriptive, as a function of instruction condition (with standard errors). $\eta_{p}^{2}=.08$. and more pronounced effects among participants in the suppression, $F(2,68)=15.32, p<.001, \eta_{p}^{2}=.31$, and prime conditions, $F$ $(2,68)=17.81, p<.001, \eta_{p}^{2}=.34$ (see Fig. 2 ).

\section{Mediation}

Mediation analyses were carried out to test the hypothesis that changes to the self-concept underlie the effects of stereotype activation on behavior. Because the type of behavioral measure did not interact with the instruction manipulation, standardized walking speed and (reflected) memory scores were averaged to form a single behavior stereotypicality index. In addition, a self-stereotype assimilation score was computed as the difference in the proportion of 'yes' responses to stereotypic vs. counter-stereotypic traits (with higher scores indicating greater self-stereotype assimilation). ${ }^{3}$

First, the steps suggested by Baron and Kenny (1986) were followed (see Fig. 3), with instruction entered as the predictor variable, self-stereotype assimilation as the mediator, and behavior stereotypicality as the outcome variable. Regression analyses indicated that all paths were significant (largest $p=.03$ ). The procedures outlined by Preacher and Hayes (2008) for testing mediation with small samples were then followed and indicated that self-stereotype assimilation was a significant mediator of behavior (bootstrap estimate of the indirect effect $=0.45 ; 99 \%$ confidence interval $=+0.04$ to +1.32 ). Importantly, the reverse mediation model was nonsignificant (bootstrap estimate of the indirect effect $=0.05,99 \%$ confidence interval $=-0.01$ to +0.11 ).

\section{Discussion}

The results of this study build on those reported by Wyer, Mazzoni, et al. (2010) by providing direct evidence that changes in the selfconcept contribute to the effects of concept activation on behavior. Participants for whom elderly stereotypes were activated produced stereotype-consistent behaviors (walking slowly, being forgetful) to a greater extent than did control participants. More importantly, these differences were significantly mediated by the extent to which participants attributed elderly-stereotypic traits to themselves.

The present research is, to our knowledge, the first to directly demonstrate mediation of behavioral assimilation effects via changes

\footnotetext{
${ }^{3}$ Preliminary analyses including trait valence revealed that participants endorsed more positive $(M=.72, s=0.14)$ than negative traits $(M=.31, s=0.15), F(1,46)=158.48$ $p<.001, \eta_{p}^{2}=.78$. Valence did not interact with any other variable and was therefore dropped from further analyses.
} 


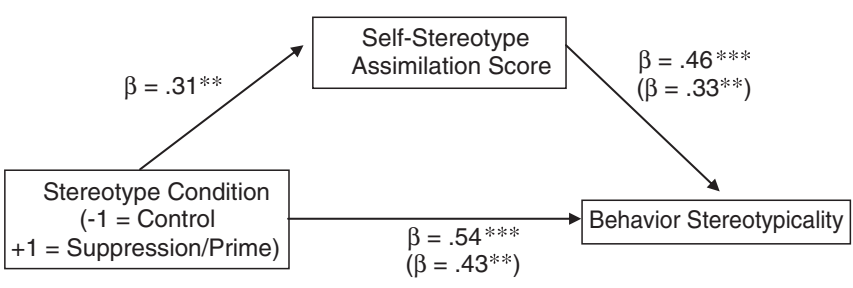

Fig. 3. Self-stereotype assimilation as a mediator of the effect of stereotype suppression and priming on behavior. Regression coefficients outside of parentheses reflect direct effects; those within parentheses reflect effects with all variables in the model.

in the active self (Wheeler et al., 2007). These results provide a parallel to Smeesters et al.'s (2009) recent report that behavioral response effects are mediated by changes in how others are perceived. Taken together, these findings support an indirect model. They suggest that social concepts - once activated - may be applied to a variety of targets (including the self or others). The manner in which they are applied, then, becomes a crucial determinant of how overt behavior is affected.

Recent research by the present authors (Wyer, Perfect, Neilens, Mazzoni, \& Roper, 2011) and others (DeMarree \& Loersch, 2009; Wyer, Calvini, et al., 2010) suggests that focus of attention is an important factor in deciding how an activated concept is applied. When a perceiver's attention is focused on another person, the concept is likely to bias one's perceptions of that person and thus encourage a response appropriate to that perception (e.g., Smeesters et al., 2009). In contrast, when attention is focused on the self - as may often be the case when one behaves in isolation from others (Wyer et al., 2011) - the concept may instead alter the active self and result in behavioral assimilation (see also DeMarree et al., 2005).

It is important to acknowledge that mediation of behavior via changes to self-perception was only partial. A significant direct effect of suppression/priming remained even when self-concept was included as a mediator. Although this may have resulted in part from the general nature of the self-concept measure (which did not specifically focus on speed or memory), it is also plausible that other mechanisms (including direct activation of behavioral representations) contributed to the behavioral effects. Stereotype activation is likely to be dynamic in its effects, with changes to the self-concept operating in parallel with other effects to impact on behavior. Likewise, the self-concept itself may be impacted by stereotype activation in both direct and indirect ways (e.g., Skowronski et al., 2010).

Thus, a more complex picture is beginning to emerge about how stereotype activation influences behavior. While this study, among others, does not contest the likelihood that some prime-to-behavior effects are direct and unmediated (as suggested by the ideomotor model), it provides supportive evidence that such effects are - in some circumstances - influenced by cognitive operations on activated concepts. The present study also adds to recent evidence (e.g., Wyer, Mazzoni, et al., 2010) that thought suppression yields changes to the active self and to behavior in ways similar to those produced by priming. In doing so, the current work broadens the realm of potential unintended influences on behavior.

\section{References}

Bargh, J. A., Chen, M. \& Burrows, L. (1996). Automaticity of social behavior: Direct effects of trait construct and stereotype activation on action. Journal of Personality and Social Psychology, 71, 230-244.

Baron, R. M., \& Kenny, D. A. (1986). The moderator-mediator variable distinction in social psychological research: Conceptual, strategic and statistical considerations. Journal of Personality and Social Psychology, 51, 1173-1182.

Bong, M., \& Skaalvik, E. M. (2003). Academic self-concept and self-efficacy: How different are they really? Educational Psychology Review, 15, 1-40.

DeMarree, K. G., \& Loersch, C. (2009). Who am I and who are you? Priming and the influence of self versus other focused attention. Journal of Experimental Social Psychology, 45, 440-443.

DeMarree, K. G., Wheeler, S. C., \& Petty, R. E. (2005). Priming a new identity: Selfmonitoring moderates the effects of nonself primes on self-judgments and behavior. Journal of Personality and Social Psychology, 89, 657-671.

Devine, P. G. (1989). Stereotypes and prejudice: Their automatic and controlled components. Journal of Personality and Social Psychology, 56, 5-18.

Dijksterhuis, A., Aarts, H., Bargh, J. A., \& van Knippenberg, A. (2000). On the relation between associative strength and automatic behavior. Journal of Experimental Socia Psychology, 36, 531-544

Dijksterhuis, A. \& Bargh, J. A. (2001). The perception-behavior expressway: Automatic effects of social perception on social behavior. Advances in Experimental Social Psychology, 33, 1-40.

Hansen, J., \& Wänke, M. (2009). Think of capable others and you can make it! Selfefficacy mediates the effect of stereotype activation on behavior. Social Cognition, 27, 76-88.

Higgins, E. T., Rholes, W. S., \& Jones, C. R. (1977). Category accessibility and impression formation. Journal of Experimental Social Psychology, 13, 141-154.

Kay, A. C., \& Ross, L. (2003). The perceptual push: The interplay of implicit cues and explicit situational construals on behavioral intentions in the Prisoner's Dilemma. Journal of Experimental Social Psychology, 39, 634-643.

Macrae, C. N., Bodenhausen, G. V., Milne, A. B., \& Jetten, J. (1994). Out of mind but back in sight: Stereotypes on the rebound. Journal of Personality and Social Psychology, 67, 808-817.

Mussweiler, T. (2007). Assimilation and contrast as comparison effects: A selective accessibility model. In D. A. Stapel, \& J. Suls (Eds.), Assimilation and contrast in social psychology (pp. 165-185). New York: Psychology Press.

Preacher, K. J., \& Hayes, A. F. (2008). Asymptotic and resampling strategies for assessing and comparing indirect effects in multiple mediator models. Behavior Research Methods, 40, 879-891.

Skowronski, J. J., Sedikides, C., Heider, J. D., Wood, S. E., \& Scherer, C. R. (2010). On the road to self-perception: Interpretation of self-behaviors can be altered by priming. Journal of Personality, 78, 361-391.

Smeesters, D. H. R. V., Wheeler, S. C., \& Kay, A. C. (2009). The role of interpersonal perceptions in the prime-to-behavior pathway. Journal of Personality and Social Psychology, 96, 395-414

Smeesters, D. H. R. V., Wheeler, S. C., \& Kay, A. C. (2010). Indirect prime-to-behavior effects: The role of perceptions of the self, others, and situations in connecting primed constructs to social behavior. Advances in Experimental Social Psychology, 42 , 259-317.

Wegner, D. M. (1994). Ironic processes of mental control. Psychological Review, 101, 34-52.

Wheeler, S. C., DeMarree, K. G., \& Petty, R. E. (2007). Understanding the role of the self in prime to behavior effects: The active-self account. Personality and Social Psychology Review, 11, 234-261.

Wyer, N. A., Calvini, G., Nash, A., \& Miles, N. (2010). Priming in interpersonal contexts: Implications for affect and behavior. Personality and Social Psychology Bulletin, 36 , 1693-1705.

Wyer, N. A., Mazzoni, G., Perfect, T. J., Calvini, G., \& Neilens, H. L. (2010). When not thinking leads to being and doing: Stereotype suppression and the self. Social Psychological and Personality Science, 1, 152-159.

Wyer, N. A., Perfect, T. J., Neilens, H., Mazzoni, G., \& Roper, J. (2011). With or without you: Determinants of post-suppression behavior. Social and Personality Psychology Science, 2, 272-276. 